De Mol., J., Reijmers, E., Verhofstadt, L., Kuczynski, L. (2018). "Reconstructing a Sense of Relational Agency in Family Therapy"

\begin{abstract}
The concept of agency is relevant in family therapy. As family therapists we approach each family member as a full agent, which means that what each person thinks and feels, makes sense, and that each person contributes in a significant way to the construction of a relationship. A person's sense of relational agency is constructed in relationships through processes of relational influence. Thus, agency is a relational construct and is dependent on bidirectional transactions in a relationship. A person's sense of relational agency refers to the sense a person has about having an influence on another person, that this influence is significant for the other, makes a difference for the other, and contributes to the construction of the relationship. Many family members who enter therapy have lost their sense of relational agency. In this paper we discuss ideas how to reconstruct family members' sense of relational agency in therapeutic practice.
\end{abstract}

Key words: agency, dialectics, family therapy, relational influence, responsiveness, therapeutic alliance

Number of words: 6078 
Key points:

- Importance of the concept of sense of relational agency for psychotherapy

- Conceptual tools to think about processes of relational influence in relationships

- Framework to do something with clients' massive feelings of disadvantage

- Draws the attention of the therapist to the effects of communications and interactions in family therapy

- Stimulates the inner dialogue of the therapist 
Reconstructing sense of relational agency

The concept of human agency has been studied both in the domain of family therapy (Madsen, 2007; Mutchler \& Anderson, 2010; Tomm, 1989; White \& Epston, 1990) and in psychological research (Bandura, 2006; Deci \& Ryan, 2002). Considered as an individual construct, human agency refers to the ontological nature of humans as intentional, selforganizing, proactive, self-regulating, and self-reflecting beings who actively contribute to their life circumstances (Bandura, 2001). Family therapists routinely approach humans as agents, by taking a collaborative and participative stance in the therapeutic relationship, and by focussing on reconnecting persons as agents to their own intentions, wishes, thoughts, and emotions (Bertrando \& Arcelloni, 2014; White, 2007). However, an individualistic conception of agency is insufficient because family therapists also focus on interpersonal processes in family and other close relationships, and stress their importance for humans' psychological, relational, and emotional well-being. Therefore, when considering the context of interpersonal relationships, human agency has to be understood as a relational concept. A person's sense of agency is inherently relational because how one acts and perceives oneself as an agent depends on the social and relationship context in which they enact and experience their agency. The concept of relational agency emphasizes the importance of interpersonal processes for constructing a person's sense of relational agency within a particular context (Sugarman \& Martin, 2011). The objective of this paper is to explore the relevance of the construct of sense of relational agency for family therapy. A particular focus concerns how a person's sense of relational agency can be fostered by exploring the experience of agency during interpersonal processes of influence and communication in family and other close relationships. The first part of the paper discuses theoretical concepts for understanding a sense of relational agency. The second part will explore how relational theory can be translated into therapeutic practice. 


\section{Theoretical concepts}

\section{Relational agency}

The concept of relational agency can be partitioned for analytical purposes into autonomy, construction, and action, which jointly considers the complex of interdependent motivations, cognitions, and actions that feed into causal processes (Kuczynski, 2003). Autonomy is the motivational aspect of agency and refers to a person's need for feeling effective in one's interactions with others, for perceiving oneself as a source for one's own actions. People may resist the actions of another when it infringes on their autonomy but simultaneously stay dependent upon others to be recognized in their autonomy. Construction refers to people's capacity to make sense of their own behaviour and the behaviours of others and to construct new meanings from these experiences. The process of sense making involves both emotions and cognitions. Finally, action refers to people's capacity to have an effect on other persons by acting or by refraining from acting on others. By acting or withdrawing from action, people have an effect on others and can induce change in the relational dynamics between oneself and the others. When individuals act as agents, autonomy, construction, and action, are experienced in an interdependent embodied way. The concept of embodiment signifies that we influence and are being influenced through our body, and it is our body that forms the bridge between the personal, relational, and socio-cultural level (Andersen, 2007; Overton, Mueller, \& Newman, 2008; Varela, Thompson, \& Rosch, 2016). Therefore, construction of meaning is an embodied action and is experienced as including relational meanings, in which persons create unique meanings about themselves in relation to others.

\section{The process of relational influence}

As agents engaging in relationships with other persons who are also agents, we continuously influence other people and are continuously influenced by others. Relational influence is the interpersonal process by which humans affect each other's emotions, 
thoughts, and behaviour (Huston, 2002). A person's sense of relational agency is constantly constructed through experiences of having relational influence on others and being relationally influenced by others. What we do (and don't do) is meaningful to others and what others do (and don’t do) is meaningful to us (Anderson \& Gehart, 2007). Within this process meanings about oneself, the other, and the relationship are continuously created and constructed.

A mother and her 16-year-old daughter visit our clinical practice because of severe tensions in their relationship. The quarrels are about the eating problems (bulimia) of the daughter and about the fact that she does not respect her parents' rules. She is often late home, visiting cafes and friends, smokes cigarettes and does not talk to her parents. Her mother is worried and angry. All conversations turn into conflicts. The mother thinks that her daughter is irresponsible and emotionally unstable and the daughter thinks her mother is overanxious and intrusive. Mother feels helpless and daughter does not feel recognized.

A core feature of processes of relational influence regards its dialectical nature (Kuczynski \& De Mol, 2015). A dialectical framework asserts that any holistic system consists of opposing forces which continuously interact to change the system to qualitatively new states of being, including novel contradictions which set the stage for further change (Baxter \& Montgomery, 1996). Applied to the context of family relationships, a dialectical perspective implies that relational influence is transactional in nature: as family members coact as agents they continuously produce qualitative change and novelty as they interpret each other's behaviour and construct meanings from their interactions.

The transactional process by which relational influence occurs is further explicated by the processes of internalization and externalization (Lawrence \& Valsiner, 2003). Internalization is the cognitive and emotional processing that takes place as people evaluate and attempt to understand others based upon their personal and relational needs, expectancies, 
and beliefs. Externalization is the further processing that takes place as people act upon the meanings constructed via internalization. Thus, meaning construction occurs at two levels. Messages and behaviour of other persons are interpreted and transformed as they are internalized, and these meaning constructs are again interpreted and transformed for action with others as they are externalized. When it is considered that when two people communicate, each transforming messages in the process of internalizing and externalizing, it is apparent that relational influence is dialectical or nonlinear, and not, deterministic or linear, because cognitive and emotional constructive meaning processes always mediate interpersonal dialogues.

\section{Sense of relational agency}

One's sense of relational agency plays a part in all social interactions but it is of special interest in close relationships. In close relationships people need to have a sense of relational agency to create intimacy and to experience interconnectedness. Having a sense of relational agency means that a person has a feeling and an awareness of making a difference in the relationship - that as an agent one can add something what is meaningful for the other, for oneself, and for the relationship (Bertrando \& Arcelloni, 2014; De Mol \& Buysse, 2008; Sugarman \& Martin, 2011). The concept of sense of relational agency must be distinguished from Bandura's concept sense of self-efficacy. Having a sense of relational agency is not about having control on the other by acting in strategic ways to achieve particular outcomes in the relationship. Control implies a mechanistic conception of influence including a linear association between cause and effect: one does something and consequently will have that specific effect on the other, independent of the agency of the person, their specific relationship, and the context. When one considers social interactions as the co-action of agents in an interpersonal relationship one must abandon a mechanistic idea of one individual causing the behaviour of another individual and replace it with a dialectical model of 
influence where relationship partners are both agents who both continuously construct new meanings during their transactions with each other.

In this way, having a sense of relational agency implies a decoupling of intentions and effects. Because of our dependency upon the interpretations of others, we can never control or predetermine our effects on others, both when our intentions are well-meant and also when they are not well-meant. However, when a person has lost or is losing a sense of relational agency within a relationship, this person may resort to power and try to control the other, with the unintended consequence of alienating oneself, the other, and the relationship. A family comes to our practice because of the unmanageable behaviour of their 14-year-old son. He wants to control everything and gets angry when his mother, father and sister do not listen to his demands. He decides which TV show must be on, commands that his mother brings him by car to school or that his father has to bike with him. Mother, father and sister all feel terrorized. Asking the son why he behaves that way, he says that his parents want to decide everything at home. They do not listen or take him seriously. The parents respond, saying that he does not listen to them. Both the parents and the boy feel that they are coerced and also ignored by the other. Neither feels a sense of relational agency.

\section{Isolated versus connected agents: the relationship context of agency}

The construction of a person's sense of relational agency is a complex interdependent phenomenon because of the dialectical nature of relational influence. On the one hand, a person can develop a sense of relational agency by making a difference in others or by resisting, contradicting, or differing from them. However, on the other hand, one's agency has to be recognized by others. This interpersonal process of being recognized by others is called perceived partner responsiveness (Reis, 2014). People interpret the responses of others and construct meanings such as being understood by the other, or being validated by the other, or that one matters to the other (Marshall \& Lambert, 2006). 
This duality underlying the construction of a sense relational agency engages two competing individual drives regarding a person's relational development, the need to develop one's own agency in the relationship and the need to be connected to the other (Baumrind, 2012; Horowitz, 2004). When the dialectics between these competing drives is constructive, the development of a connected agency is possible. Connected agents are persons who deploy their agency in relationships but simultaneously feel connected and take care to stay connected to the relationship. For example, research indicates that adolescents in nonclinical samples exercise their autonomy by resisting parental expectations in a way that protects or accommodates their relationship with parents (Parkin \& Kuczynski, 2012). Only connected agents can develop an adaptive sense of relational agency. When one is losing connection with the other in the relationship, that is, when a person as an agent doesn't feel recognized by the other, one is losing his or her sense of relational agency in this relationship, and is becoming an isolated agent. Moreover, as an isolated agent one is not only becoming alienated from the other but also from one's own emotions and cognitions due to a lack of embodiment. As our body forms the bridge between the personal, relational, and sociocultural level (Anderson, 2007; Overton, Mueller, \& Newman, 2008; Varela, Thompson, \& Rosch, 2016), one can only feel what one feels and can only understand what one thinks by acts of recognition of the other.

One can glimpse what it feels like to be an isolated agent when one interacts with or tries to persuade a complete stranger. Because one has no history of connection, one does not know what to do, or what to expect, and, indeed, knowing that the other is a complete stranger with whom one has no connection means that the other's unresponsiveness and lack of recognition has little significance for one's sense of relational agency. However, when one is becoming an isolated agent in family or other close relationships, the process of alienation 
from one's own wishes, intentions, emotions, and thoughts is much enhanced and sense of relational agency in these relationships is diminished.

Because the development of connected agency is a relational as well as a bidirectional phenomenon, both relationship partners contribute to the construction of the relationship and one's sense of relational agency in that relationship. In the case of parent-child relationships, parents and children are equally agents with capacities for construction, action and autonomy (Kuczynski, 2003). This means that both the parent and the child add meaningful elements to the construction of the other person's sense of relational agency. Being equally agentic does not exclude a hierarchical relationship between parents and children. Parents have more power resources and bear more responsibilities, but because the relationship is interdependent, parents still depend upon acts of recognition of their children regarding their identity as parents and their ability to construct a mutual intimate relationship with their children.

\section{Therapeutic applications}

The objective of this section is to discuss the usefulness of the theoretical concepts of relational influence and sense of relational agency for therapeutic practice. Theoretical concepts provide frameworks that may help us as therapists to understand something of the complexities with which we are confronted. Although theoretical concepts don't tell us what we have to do or how we have to do it, they can enrich our therapeutic creativity. In this section we discuss in particular how isolated agents can reconstruct a sense a relational agency.

\section{The process of relational influence: disconnecting inside - outside - other side}

Earlier, the processes of internalization and externalization were used to explain the nonlinear nature of relational influence. In order to translate the abstract scientific constructs of internalization and externalization into a form that can be used in clinical practice, we 
introduce the therapeutic metaphor of developing and experiencing the inside (as a result of internalization) and dialoguing via the outside (as a result of externalization). The inside consists of cognitions and emotions about the other and the nature and status of one's relationship with the other. People disclose the inside to others through the outside (the process called externalization), that is, behaviour, facial expression, body posture, verbal and nonverbal expressions, as well as cognitive content of the dialogue. By means of the outside we affect the other person (the other side).

In a therapy session a 17-year-old girl describes how upset and bewildered she is that her brother, sister and her classmates accuse her of being arrogant. When the therapist asks what her classmates can see that might account for this view of her, she answers after a short silence: 'When I feel uncomfortable, I don't say much, I don't laugh or don't react spontaneously'. The therapist says: 'On your inside you feel uncomfortable and uncertain, but they can only see your outside and think that you are confident and arrogant. That must be very confusing'.

The other person (the other side) has also processes of internalization (leading to an inside) and externalization (leading to an outside). The person interprets and experiences the other's behaviour, attributes meaning to it, feels something about it, and ultimately responds or externalizes on the basis of that interpretation and feeling. When people relate, communicate, and interact, they have all kinds of thoughts, feelings, and bodily sensations: they have desires, motivations, beliefs, intentions, and so on. This inside is not visible or directly perceptible for the person and for others. The inside does not live in a glasshouse. This can be advantageous and disadvantageous. For example, we can keep things to ourselves and create privacy, but doing so can lead to misunderstanding. People cannot switch off their appearance and emotional reactions, thus people continuously influence without awareness or intention and produce unintended consequences of influence. Even if people act strategically 
and intentionally, the meaning of their actions will be determined by the other person's interpretation as an emotional, cognitive, and embodied action.

By separating inside - outside - other side the therapist can make a bridge between the individual and the relational dimension, by giving recognition and words to the inside of a person and simultaneously dialoguing about possible effects on others without judging or accusing the inside of the person and also of the others. In the case of the 17-year-old girl, the therapist can give recognition at her inside and simultaneously facilitate a dialogue about effects, because these effects on others are not associated with her inside or intentions, but with the inside of the others. Moreover, each person has their own inside, which complicates the process of constructing a sense of relational agency in different close relationships.

\section{Dimensions of sense of relational agency}

In order to discuss the process of reconstructing in dialogue with our clients some sense of relational agency, it is therapeutically useful to make a distinction between several dimensions of sense of relational agency. First, regarding sense of influencing, one can have a sense of intentionally or unintentionally influencing another person in a constructive way. Constructive influence reflects a feeling and awareness that as an agent you can make a positive difference for the other person: what you do or do not do can have positive meanings for the other person in the relationship. Second, one can have a sense that the consequences of their influence are unpleasant, hurtful, or even damaging to the relationship partner. Constructive influencing and destructive influencing do not imply the intentionality of the person who influences but they do convey an awareness and feeling of the positive or negative consequences for the relationship. Third, in regard to the facets of being influenced, one can have a feeling and awareness of being influenced by another person in a constructive way, or in other words, having a sense that another person's influence has consequences that are positive and pleasant. Fourth, one can have a sense of being influenced by the other 
person in way that is negative or hurtful for oneself. Both constructive and destructive facets of the sense of being influenced do not imply the intentionality of the person whose influence is felt. A sense of relational agency concerns the meanings regarding the other's externalized behaviour that the individual developed within the context of the relationship.

In everyday life people experience each of these dimensions of sense of relational agency. Depending on the situation, relationship context, frame of mind, and many other factors, a specific sense of relational agency may be experienced. When all of these dimensions of sense of relational agency are present to some extent in daily life, people stay connected to the complex reality of social life. Sometimes you can please someone, but with the same behaviour hurt another one. Someone can have an effect on you that is pleasant, but the same person can hurt you in another context by doing just the same thing. The nonlinear nature of relational influence is taken for granted and compensated for by connected agents who have a sense of relational agency. Connected agents have an implicit understanding that influence is nonlinear and governed by the interpretive processes of both individuals. They do not have the unrealistic expectation that they should have a linear influence on the other and may have a greater awareness of the many forms that relational influence takes. However, people who experience difficulties in life and are isolated agents have problems with perceiving themselves as influencing or being influenced.

\section{The context of family therapy}

Our main hypothesis, based on clinical practice, is that clients who enter therapy have lost their sense of relational agency in one or more important life domains. The different dimensions of sense of relational agency can be conceptual and therapeutic tools to understand our clients and to explore with them the complexity of social life in order to reconstruct with them some sense of relational agency. 
Developing a sense of being negatively influenced. At the start of a

psychotherapeutic process, many clients tell stories about being hurt, misunderstood, rejected, teased, denigrated, or assaulted by others. They often experience these feelings in an overpowering and undifferentiated way. The basic feeling is one of disadvantage or being badly treated by others. Some cope with this feeling through processes directed towards the external world (e.g., aggressive behaviour), others through processes directed to oneself (e.g., depression). When people live in a world of disadvantage and experience massive feelings of being badly treated by others, it is difficult to address immediately their constructive agentic capacities in relationships. Therefore, it can be useful to explore with clients a sense of being negatively influenced by others. By doing this, the therapist is not only constructing a relationship by acts of recognition and empathy, but also is reconnecting the client to social life by addressing the reality of their feelings of disadvantage - as an agent one is allowed to have these feelings. In family therapy this is not a small task. Having empathy for one person can create a disconnection with another family member, with consequences such as denial, escalation, and estrangement. By exploring the experiences and feelings of clients within specific contexts, clients and therapist search for words and try to give language to these negative feelings and experiences. Language creates personal and relational realities, and it is by giving words to the clients' inside that their inside obtains the right to exist within their social and relational world (Madsen, 2007). By collaborative searching and finding words for a person's inside, the person can feel what he/she feels.

Therefore, in family therapy, it is useful to explore with clients the complexities of their social-relationships outside the family and asking if there is someone in that context who can recognize something of these complexities. These interventions facilitate processes of perceived partner responsiveness in family relationships and other interpersonal contexts. By exploring with the family the relational complexities that exist for each family member, the 
family is approached as a resource and not as the problem, which facilitates processes of recognition and responsiveness inside the family. Recognizing and validating a person's inside does not mean approving these feelings and cognitions. But, when clients' experiences of being negatively influenced are recognized, they can develop a sense of this particular influence - it is a reality, it exists, they are allowed to feel it, and it happens in social and relational life. The field of relationship research indicates that relational life is difficult and complicated because of its interdependent nature (Horowitz, 2004). Consequently, feelings and thoughts of being badly, unfairly, and incorrectly treated by others belong to relational life and is experienced as reality.

A father and a mother of a one-year-old daughter consult us. The mother feels very depressed and is weighed down by feelings of guilt. She constantly thinks that she is a bad mother. She is convinced that as a responsible mother she must make her child happy every minute of the day. This makes her anxious and preoccupied with her own shortcomings. The father recognizes the burden of parenthood. He feels bad and gets angry when his parents or his parents-in-law say what he must do or not do with his child. The father tries to comfort the mother. He thinks that she worries too much: 'Be more positive', is his advice. 'And', he adds, 'go out, do something nice, visit your friends.' Such advice feels unhelpful and oppressive to her. She tried everything, but could not change the way she thinks and feels and she gets more anxious when the baby is not with her. We decide that talking about how to change things does not help her. The negative influence is too overwhelming. But when we explore if other mothers also experience these pressures and anxieties, a more serious conversation unfolds. Unwanted advice, worries, and feelings of guilt are the burdens of motherhood. That is what children 'do to you' and it is a huge undertaking to be a parent without being overwhelmed.

Developing a sense of constructive influencing. The experience and especially the acknowledgment of the experience that a person can please another person or have an 
influence that is constructive for that other person is of vital importance for the development of a positive identity, self-confidence, and a satisfying relationship. Therefore, in order to reestablish this sense of relational agency, it is important that this constructive form of relational influence is acknowledged by other persons, inside and outside the family. It implies letting go of one's perspective and giving priority to the interpretations and meanings constructed by the other person. The uncontrollability of interpersonal processes because of the difference between intentions and effects, means that one has constructive influences on others that are nonlinear and not linked with one's own intentions. One can intend to have a constructive influence on another but the constructive nature of these effects depends on the other's perception and interpretation. The development of a sense of constructive influencing also depends on cultural, local, and family habits and practices. Within a social context where it is not customary to make compliments, it may be more difficult to develop this sense of constructive influencing. Moreover, within a culture where the idea exists that it is rather normal and evident to have constructive effects on others, it can be difficult for a person to sense what it means for oneself to have constructive effects. Accepting the recognition of others means actively constructing one's own sense of constructive influencing and identity. A couple comes to therapy. The woman is irritated by her partner, because he does not communicate his own opinions. She says that what she wants is what he wants. The man is puzzled by his wife's criticism. He says that he follows her lead and does everything to please her, but she is never satisfied. Both can articulate the negative effect of the other partner and both insist that the other must change. We ask if sometimes, in the present or in the past, they felt that they have done something the other liked. After a brief silence the women tells that in the past she often surprised her husband. She bought tickets for concerts and film or surprised him by arranging short holidays. She liked to do unexpected things and he enjoyed it. The man nods and smiles. Then he recalls that when his wife had some trouble with her 
boss, he listened to her and gave her advice. That was a real support for her. We talk about their strengths, that she is interesting and unpredictable and that he a good listener. We ask the couple if and how they want to introduce this again in their relationship. They want it back, but also change things. We then explore the possibilities for her to be more unpredictable again and to express tentativeness and uncertainty of her opinions, and for him to be a good listener again and to bring his own ideas into action.

Developing a sense of being constructively influenced. The development of a sense that one is being influenced in a positive manner goes hand in hand with the development of sense of constructive influencing. In order to perceive a constructive influence from another person it is essential that the relational context affords the right to be influenced in this way, without minimizing or rejecting it. In order to construct this dimension of sense of relational agency people must have some sense that they are agents who are relationally connected and embedded within their family and social context. Accepting and incorporating constructive influences from others is only possible when family members feel connected to the communality of being a family. When there is insufficient connectedness, and conflicts or disagreements are overwhelmingly present, it is very difficult to acknowledge constructive influences from others because these influences may be perceived as manipulative or false. Moreover, the development of this dimension also depends on practices typical of social contexts in which people live. Within certain socio-cultural and family contexts it may be embarrassing for a person to receive constructive comments, as this person may be suspected of flattery.

The couple mentioned above could have a more constructive conversation because they could remember and talk about situations in which they had experienced moments of positive mutuality where they had a positive influence on the other partner. Also important was the mutual recognition of this positive effect. A context was created in which it was 
possible to sense that positive mutuality was a possibility because the other constructively influenced them in the past. When this happens, relational intimacy or connectedness is felt (Weingarten, 1992).

Developing a sense of negative influencing. In real life it is unavoidable that one person in a close relationship will hurt another person. Although a person can hurt another person intentionally, such actions are connected with feelings of being disadvantaged by others. Most frequent are instances of negative influencing which pertain to interpersonal slights stemming from bidirectional moments in social interactions and not permanent feelings in the relationship. Therefore, in order to develop a sense of negative influencing it is necessary to separate intentions from outcomes, which means that the awareness that hurting another person may have nothing to do with the intention to hurt. Although this sense of negative influencing is about damaging consequences for the other person, from a relationalethical point of view this temporary sense of negative influencing may be constructive. For example, a father who punishes his child feels that this is unpleasant for the child and also for himself, however, this father also understands that having this negative effect is unavoidable and also might be constructive for the child. This does not mean that a person always can have this sense of negative influencing. All dimensions of relational influence are more or less present in daily life and in the realm of normal experience.

People who continuously live with this sense of negative influencing would always feel and be aware, even during intense relational conflict and personal distress, that their actions have consequences that can be unexpected and hurtful for other persons. Taking these complications into consideration, it is constructive that people have this particular sense of negative influencing only occasionally, and this sense may vanish rapidly considering the vitality of relational life. The father, who understands that punishing his child is sometimes unavoidable and necessary, also can feel bad or guilty about doing this. 
In a therapy session with a single father and his 13-year-old daughter the father forbids his daughter to go with her friends to a disco. 'All my friends go', she argues, 'and the band that plays is very famous.' It will be a big party, till far after midnight. Father is deaf to his daughters' arguments and she gets angrier and angrier. She jumps of her chair, leaves the therapy room and slams the door. Father feels uncomfortable and ashamed. This is how it always goes. But he is convinced that she is still too young to go to parties. He believes that his resistance as father is the best thing for his daughter. He is fully aware of the negative impact this has on his daughter. But he is also very afraid about what these conflicts mean to their relationship. He feels depressed by them. So should he give in to her despite his concerns about her safety? Confusing.

\section{Implications for the therapeutic alliance}

As therapists we need ideas, concepts and models to give us something to hold on to during therapeutic sessions. Metaphorically speaking, we have a backpack carrying these resources. The concept sense of relational agency and its dimensions can be helpful to guide therapists in the tangle of interactions, emotions, intentions, and effects. Therapists sometimes feel disillusioned about the progress in therapy. They get stuck or are overwhelmed by the effects clients have on them and on each other. The finding that clients, despite every effort of the therapist, cannot see their own contributions to the difficulties is discouraging. In this way, we as therapists may lose our sense of relational agency during therapy sessions and get stuck in a world of disadvantage.

However, having a sense of being negatively influenced can be constructive for the therapist. Because constructing a sense of relational agency is always a bidirectional process, recognizing a sense of being negatively influenced tells the therapist something about what is happening in the therapy room and also in the family and social context of the clients. As 
therapists we are allowed to have a sense of being negatively influenced because of the dialectical nature of influence. Current evolutions in the world of family therapy can induce an illusion of control with the therapist, due to a mechanistic or linear conception about influence in the protocols: when the therapist act in this way the therapist will have that outcome. An appreciation of the dialectical nature of relational influence allows us as therapists to fail, because we cannot control our clients. Given the complexity of relational agency, if the therapist can help develop some dimensions of sense of relational agency with the family members and himself or herself, he or she has reached an important progress. 


\section{References}

Andersen, T. (2007). Human participating: Human "being” is the step for human 'becoming' in the next step. In H. Anderson \& D. Gehart (Eds.), Collaborative therapy: Relationships and conversations that make a difference (pp. 81-93). New York: Routledge.

Anderson, H. \& Gehart, D. (2007). Collaborative therapy: Relationships and conversations that make a difference. New York: Routledge.

Bandura, A. (2001). Social cognitive theory: An agentic perspective. Annual Review of Psychology, 52, 1-26. doi: 10.1146/annurev.psych.52.1.1

Bandura, A. (2006). Towards a psychology of human agency. Perspectives on Psychological Science, 1, 164-180. doi: 10.1111/j.17456916.2006.00011.x

Baumrind, D. (2012). Differentiating between confrontive and coercive kinds of parental power-assertive disciplinary practices. Human Development, 55, 35-51. doi: $10.1159 / 000337962$

Baxter, L. A., \& Montgomery, B. M. (1996). Relating: Dialogues and dialectics. New York : Guilford Press.

Bertrando, P., \& Arcelloni, T. (2014). Emotions in the practice of systemic therapy. Australian and New Zealand Journal of Family Therapy, 35, 123-135. doi: 10.1002/anzf.1051

Deci, E. L., \& Ryan, R. M. (2002). Handbook of self-determination research. Rochester, NY: University of Rochester Press.

De Mol, J., \& Buysse, A. (2008). The phenomenology of children's influence on parents. Journal of Family Therapy, 30, 163-193. doi: 10.1111/j.14676427.2008.00424.x Horowitz, L.M. (2004). Interpersonal foundations of psychopathology. Washington: American Psychological Association. doi: 10.1037/10727-000 
Huston, T. L. (2002). Power. In H. H. Kelley, E. Berschied, A. Christensen, J. Harvey, T. L. Huston, G. Levinger, E. McClintock, L.A. Peplau, \& D.R. Peterson (Eds.), Close relationships (pp. 169-219). New York: Freeman.

Kuczynski, L. (2003). Beyond bidirectionality: Bilateral conceptual frameworks for understanding dynamics in parent-child relations. In L. Kuczynski (Ed.), Handbook of dynamics in parent-child relations (pp. 1-24). Thousand Oaks, CA: Sage.

Kuczynski, L., \& De Mol, J. (2015). Dialectical models of socialization. In W.F. Overton \& P.C.M. Molenaar (Eds.), Theory and Method. Volume 1 of the Handbook of Child Psychology and Developmental Science (7th ed.), (pp. 323-368). Editor-in-Chief: Richard M. Lerner. Hoboken, NJ: Wiley. doi: 10.1002/9781118963418.childpsy109 Lawrence, J. A., \& Valsiner, J. (2003). Making personal sense. An account of basic internalization and externalization processes. Theory and Psychology, 13(6), 723-752. doi : $10.1177 / 0959354303136001$

Madsen, W.C. (2007). Collaborative therapy with multi-stressed families (2nd ed.). New York: The Guilford Press.

Marshall, S. K., \& Lambert, J. D. (2006). Parental mattering: A qualitative inquiry into the tendency to evaluate the self as significant to one's children. Journal of Family Issues, 27, 1561-1582. doi:10.1177/0192513X06290039

Muntigl, P., \& Horvath, A.O. (2016). A conversation analytic study of building and repairing the alliance in family therapy. Journal of Family Therapy, 38, 102-119. doi: $10.1111 / 1467-6427.12109$

Mutchler, M., \& Anderson, S. (2010). Therapist personal agency: A model for examining the training context. Journal of Marital and Family Therapy, 36(4), 511-525. doi: 10.1111/j.1752-0606.2010.00198.x

Overton, W. F., Mueller, U., \& Newman, J. L. (Eds.). (2008). Developmental 
perspectives on embodiment and consciousness. Hillsdale, NJ: Erlbaum.

Parkin, C. M., \& Kuczynski, L. (2012). Adolescent perspectives on rules and resistance within the parent-child relationship. Journal of Adolescent Research, 27, 555-580. doi: $10.1177 / 0743558411435852$

Reis, H.T. ( 2014). Responsiveness: Affective interdependence in close relationships. Mechanisms of social connection: From brain to group, 255-271.

Sugarman, J., \& Martin, J. (2011). Theorizing relational agency. Journal of Constructivist Psychology, 24, 283-289. doi: 10.1080/10720537.2011.593455

Tomm, K. (1989). Externalizing the problem and internalizing personal agency. Journal of Strategic and Systemic Therapies, 8 (1), 54-59. doi:10.1521/jsst.1989.8.1.54

Varela, F.J., Thompson, E., \& Rosch, E. (2016). Embodied mind: Cognitive science and human experience (Revised edition). Cambridge, US: The MIT Press.

Weingarten, K. (1992). A consideration of intimate and non-intimate interactions in therapy. Family Process, 31, 45-59

White, M. (2007). Maps of narrative practice. New York: Norton.

White, M., \& Epston, D. (1990). Narrative means to therapeutic ends. New York: Norton. 